\title{
Pseudaestuariivita rosea sp. nov., a novel species of genus Pseudaestuariivita, isolated from Acmaea, a kind of marine mollusea
}

\section{Shuai-Ting Yun}

Shandong University

\section{Zhuo Chen}

Shandong University

Yan-Jun Yi

Shandong University

Ming-Jing Zhang

Shandong University

\section{Shu-Kun Gao}

Shandong University

Yan-Xia Zhou ( $\nabla$ zhouyx@sdu.edu.cn )

Shandong University https://orcid.org/0000-0003-0393-8136

\section{Research Article}

Keywords: Genome, Marine creature, Polyphasic analysis, Pseudaestuariivita, 16S rRNA

Posted Date: July 8th, 2021

DOI: https://doi.org/10.21203/rs.3.rs-612446/v1

License: (c) (1) This work is licensed under a Creative Commons Attribution 4.0 International License.

Read Full License 
1 Pseudaestuariivita rosea sp. nov., a novel species of genus Pseudaestuariivita,

2 isolated from Acmaea, a kind of marine mollusea.

3 Shuai-Ting Yun · Zhuo Chen · Yan-Jun Yi · Ming-Jing Zhang · Shu-Kun

4 Gao $\cdot$ Yan-Xia Zhou *

$5 \quad$ Marine College, Shandong University, Weihai 264209, China

6 *Correspondence: Yan-Xia Zhou; Email: zhouyx@sdu.edu.cn

7 Abbreviations:

8 AAI, Average Amino Acid identity

$9 \quad$ ANI, Average Nucleotide Identity

10 cAAI, core-gene average amino acid identity

11 COG, Cluster of Orthologous Group

12 dDDH, digital DNA-DNA Hybridisation;

13 GGDC, Genome-to-Genome Distance Calculator

14 HPLC, High Performance Liquid Chromatography

15 KCTC, Korean Collection for Type Cultures

16 KEGG, Kyoto Encyclopedia of Genes and Genomes

17 LPS, lipopolysaccharide

18 MA, Marine agar 2216

19 MB, Marine broth 2216

20 MCCC, Marine Culture Collection of China

21 MEGA, Molecular Evolutionary Genetics Analysis

22 NCBI, National Center for Biotechnology Information 
PC, phosphatidylcholine

PE, phosphatidylethanolamine

PG, phosphatidylglycerol

POCP, percent of conserved proteins

TLC, Two-dimensional thin-layer chromatogram

VFDB, Virulence Factors of Pathogenic Bacteria.

\section{Abstract}

A Gram-stain-negative, pink-pigmented, facultatively anaerobic, gliding and rod-shaped bacterium, showing optimum growth at $33{ }^{\circ} \mathrm{C}$, designated as strain $\mathrm{H} 15^{\mathrm{T}}$, was isolated from the gut microbial of the Acmaea from Weihai, Shandong Province, China and characterised phylogenetically, phenotypically and chemotaxonomically. Phylogenetic analysis based on 16S rRNA gene sequence comparisons revealed that the strain belonged to the family Rhodobacteraceae and was associated with members of the recognized genera, the closest relative was the type strain of Pseudaestuariivita atlantica (96.7\%). Genome analysis showed that the genome size was $3893398 \mathrm{bp}$ and the DNA $\mathrm{G}+\mathrm{C}$ content obtained from the draft genome sequence was $56.7 \%$. The secondary metabolites based on genome predicated that the strain $\mathrm{H} 15^{\mathrm{T}}$ contained one cluster of lassopeptide, one cluster of bacteriocin, two clusters of terpene production, two clusters of homoserine lactone (Hserlactone) production and one cluster of beta lactone. The average amino acid identity, average nucleotide identity and digital DNA-DNA hybridization values between genome sequences of strain 
$\mathrm{H} 15^{\mathrm{T}}$ and all the type strains of the recognized taxa compared were lower than 63.1, 72.0 and $19.7 \%$, respectively. Based on the analysis of chemical components, the predominant cellular fatty acids were summed featured $8\left(\mathrm{C}_{18: 1 \omega} 1 c / \omega 6 c, 46.1 \%\right), \mathrm{C}_{20: 1}$ $\omega 7 c(17.1 \%)$, the major polar lipids contained phosphatidylcholine, phosphatidylglycerol, phosphatidylethanolamine and an unidentified lipid and the predominant menaquinone was Q10. Therefore, the combined chemotaxonomic, phenotypic and phylogenetic data indicated that the strain was considered to represent a novel species of the genus Pseudaestuarivita and the name Pseudaestuariivita rosea sp. nov. was proposed for strain $\mathrm{H} 15^{\mathrm{T}}\left(\mathrm{MCCC} 1 \mathrm{~K} 04420^{\mathrm{T}}=\mathrm{KCTC} 82505^{\mathrm{T}}\right)$.

Keywords: Genome · Marine creature · Polyphasic analysis $\cdot$ Pseudaestuariivita $\cdot 16 \mathrm{~S}$ rRNA

\section{Declarations}

\section{Funding}

This work was supported by the National Natural Science Foundation of China (31700116), the Natural Science Foundation of Shandong Province (ZR2017MC019), the China Postdoctoral Science Foundation (2183), and the Key Science and Technology Program of Weihai (1070413421511).

\section{Authors' contribution}

YJY contributed to the sample collection and biochemical characterization. STY analysed the data and drafted the manuscript. ZC contributed to the construction of 
phylogenetic tree. MJZ contributed to revision of this article. SKG contributed to genome submission and analyses. YXZ designed the experiments and revised the manuscript.

\section{Compliance with ethical standards}

Conflict of interest The authors declare that there is no conflict of interest.

Ethical approval This article does not contain any studies with animals performed by any of the authors.

\section{Introduction}

The genus Aestuariivita, was first established in 2014 by Sooyeon Park as a novel genus and embraced 2 species, including Aestuariivita boseongensis (Park et al. 2014), and Aestuariivita atlantica (Li et al. 2015). Until 2018, the boundaries of bacterial genera based upon the multi-faceted analysis were redefined by Wirth and Whitman and proposed that Aestuariivita atlantica be reassigned to the novel genus Pseudaestuariivita with the type species Pseudaestuariivita atlantica on the basis of the low core-gene average amino acid identity (cAAI) and percent of conserved proteins (POCP) (Wirth and Whitman 2018). Therefore, the novel genus Pseudaestuariivita was constructed and at the time of writing in 2021, the genus Pseudaestuariivita comprised only one species with validly published names. The species was in description of Gram-staining-negative, oxidase-positive and catalase-negative, oval-to rod-shaped, and non-motile with grey-white-colored 
colonies (Li et al. 2015).

As described above, the novel strain $\mathrm{H} 15^{\mathrm{T}}$ was isolated from Acmaea, a kind of mollusk creature, with a description of Gram-stain-negative, pink-pigmented, motile and rod-shaped. The $16 \mathrm{~S}$ rRNA gene sequence indicated that strain $\mathrm{H} 15^{\mathrm{T}}$ belonged to the family Rhodobacteraceae and showed the highest sequence similarity value to Pseudaestuariivita atlantica KCTC $42276^{\mathrm{T}}$ (96.7\%). And other analyses were presented in this study for the specific description of the novel strain and determinization of the exact taxonomic position.

\section{Materials and methods}

Isolation and culture conditions

Strain $\mathrm{H} 15^{\mathrm{T}}$ was isolated from Acmaea, a mollusk collected from Weihai, Shandong Province, China $\left(121^{\circ} 58^{\prime} 39.9^{\prime \prime}\right.$ E, 37 $28^{\prime} 29.7^{\prime \prime}$ N). Sampling was processed in the laboratory and purified by ten-fold dilution series method. The dilution was then inoculated on marine agar 2216 (MA, Becton Dickinson). Pink colonies were obtained after incubation at $30{ }^{\circ} \mathrm{C}$ for 5 days and designated as strain $\mathrm{H} 15^{\mathrm{T}}$. The strain was then deposited at Korean Collection for Type Cultures (KCTC) and Marine Culture Collection of China (MCCC) and the experimental reference strain Pseudaestuariivita atlantica KCTC $42276^{\mathrm{T}}$ was purchased from KCTC. After purification, the isolated pure cultures were cultured under comparable conditions for physiological and chemotaxonomic features. And they were preserved frozen at $-80{ }^{\circ} \mathrm{C}$ in sterile distilled water supplemented with $1.0 \% \mathrm{NaCl}(\mathrm{w} / \mathrm{v})$ and $15.0 \%(\mathrm{v} / \mathrm{v})$ 
105

106

glycerol. When necessary, they were grown for $3-5$ days at $30{ }^{\circ} \mathrm{C}$ under aerobic condition on MA medium.

\section{Phylogenetic and genome characterization}

The 16S rRNA sequences of strain $\mathrm{H} 15^{\mathrm{T}}$ obtained was determined by PCR using bacterial universal primers (Kim et al. 2014), and the PCR product was purified using a PCR purification kit (Sangon Biotech, China). Obtained sequences were assembled using Bioedit (Tippmann 2004) and compared with those of validly published species in the EzBioCloud web service (Yoon et al. 2017a) and National Center for Biotechnology Information (NCBI) database by using BLAST search. Based on all the strains with $16 \mathrm{~S}$ rRNA sequence similarity of $95.0 \%$ above, multiple alignments of their sequences were performed using Clustal_X version 1.83 with default settings (Thompson et al. 1997). Maximum-likelihood (Felsenstein 1981) and Neighbor-Joining (Saitou and Nei 1987) phylogenetic tree was constructed for the analyses of phylogenetic and molecular evolutionary in the software package MEGA version 7.0 (Kumar et al. 2016) with the Kimura two-parameter model (Kimura 1980), and the topology of each tree was evaluated by the bootstrap analysis based on 1000 random re-samplings of the sequences.

The draft genome sequence of strain $\mathrm{H} 15^{\mathrm{T}}$ was determined using paired-end sequencing method with the Illumina HiSeq-PE150 platform. Assembly of raw reads was performed using the SOAP and Abyss software and CISA software for integration. The annotation of genome sequence was processed using the GeneMarkS, 
rRNAmmer, and Rfam software. These operations were all implemented by Beijing Novogene Bioinformatics Technology Co, Ltd. (Beijing, China). Functional annotation of sequences was performed by using Blast against the non-redundant GenBank database. The genes involved in metabolic pathways were analysed using the Kyoto Encyclopedia of Genes and Genomes (KEGG) databases (Kanehisa et al. 2016). Protein-encoding regions were identified and annotated with the Rapid $\begin{array}{lllll}\text { Annotations using } & \text { Subsystems } & \text { Technology } & \text { (RAST) server }\end{array}$ (http://rast.nmpdr.org/rast.cgi) (Aziz et al. 2008) and the UniProtKB / Swiss-Prot (Consortium 2018). Secondary metabolite was presented by antiSMASH 5.0 (Blin et al. 2019). In order to assess the pathogenic potential of the strain $H 15^{\mathrm{T}}$, Virulence Factors of Pathogenic Bacteria (VFDB) database(Chen et al. 2005) was used to offer the species information and basic description of virulence genes, detailed descriptions of virulence gene functions and pathogenic mechanisms provided as well. The DNA $\mathrm{G}+\mathrm{C}$ content of strain $\mathrm{H} 15^{\mathrm{T}}$ was determined from the genome sequence.

The average amino acid identity (AAI) (Konstantinidis and Tiedje 2005; Rodriguez-R and Konstantinidis 2014) calculator was carried out between strain $\mathrm{H}^{15^{\mathrm{T}}}$ and its closely related species (http://enve-omics.ce.gatech.edu/aai/). The average nucleotide identity (ANI) values and Digital DNA-DNA hybridization (dDDH) values were determined for the genome-based similarities, using the EzBioCloud integrated database (Yoon et al. 2017a) OrthoANIu algorithm of the EzGenome web service (Yoon et al. 2017b) and the Genome-to-Genome Distance Calculator (GGDC) version (Meier-Kolthoff et al. 2013). 
Morphology, physiology and biochemical analysis

The cell morphology, cell size, and presence of flagella were observed via scanning electron microscopy (Jem-1200; JEOL) after incubating on MA at $30{ }^{\circ} \mathrm{C}$ for 5 days. Basic phenotypic characterization such as gram staining, optimal $\mathrm{pH}$ and motility were presented as follows: growing status of strain $\mathrm{H} 15^{\mathrm{T}}$ was measured on MA at different temperatures $\left(4,10,15,20,25,30,33,37,40,42\right.$, and $\left.45{ }^{\circ} \mathrm{C}\right)$, and the optimum growth temperature was obtained from above. The $\mathrm{pH}$ tolerance range $(\mathrm{pH}$ 5.5-9.5) was determined in MB with a concentration of $20 \mathrm{mM}$ using the buffer systems as described by $\mathrm{Yin}$ (2021). Test on the effect of $\mathrm{NaCl}$ was implemented in $\mathrm{NaCl}$-free artificial seawater medium supplemented with various concentrations of $\mathrm{NaCl}$ (final concentration $0.0-10.0 \%$, in increments of $0.5 \%$ ) (Yang and Cho 2008). Gram staining was performed as described by Smibert and Krieg (Smibert and Krieg 1994). Investigation on anaerobic growth was carried out after the strain $\mathrm{H} 15^{\mathrm{T}}$ was cultured on MA with or without $0.1 \%(\mathrm{w} / \mathrm{v}) \mathrm{NaNO}_{3}$ under anaerobic conditions at $30{ }^{\circ} \mathrm{C}$ for 2 weeks. Gliding motility was observed by oil-immersion phase-contrast microscopy (AX70; Olympus) according to the method by Bowman (Bowman 2000). In addition to the fundamental activities of catalase and oxidase, hydrolysis of cellulose, agar, casein, and Tween 80 tested by the conventional procedures as described by Tindall (2007), additional physiological tests were also carried out using API 20E, API 20NE and API ZYM strips (bioMérieux) and the oxidation and fermentation of carbohydrates were detected after growth on MA at $30^{\circ} \mathrm{C}$ for 3 days using the Biolog GEN III Micro Plates and API 50CHB Fermentation Kit 
170 (bioMérieux) according to the manufacturer's instructions. Antibiotic sensitivity was 171 assessed on MA plates with discs (Tianhe) containing various antibiotics for 3 days at $17230^{\circ} \mathrm{C}$

Chemotaxonomy

174 Chemotaxonomic characteristics of strain $\mathrm{H} 15^{\mathrm{T}}$ and the reference strain were 175 determined under similar conditions for the sake of avoiding large differences caused by the cultured environments. And the freeze-drilled strains were also needed. For the

177 analysis of fatty acid, both of strains were grown on MA medium at $30{ }^{\circ} \mathrm{C}$. The 178 cellular fatty acids were extracted, methylated and analysed by Sherlock Microbial 179 Identification System (MIDI) (Sawant et al. 2015) with the TSBA6.0 database. 180 Detection of respiratory quinone and polar lipids were completed with High 181 Performance Liquid Chromatography (HPLC) (Hiraishi et al. 1996) and the two 182 dimensional thin-layer chromatography using the method of Minnikin (1984), 183 respectively.

\section{Results and discussion}

Phylogenetic analysis

Based on 16S rRNA gene sequences extracted from the draft genome, phylogenetic analysis showed that strain $\mathrm{H} 15^{\mathrm{T}}$ shared the highest similarity with $P$. atlantica (96.7\%). In the neighbor-joining phylogenetic tree based on 16S rRNA gene sequences, strain $\mathrm{H} 15^{\mathrm{T}}$ formed a separate branch from $P$. atlantica (Fig. 1), and the 
Maximum-Likelihood phylogenetic tree showing the similar taxonomic position given in Fig. S1.

AAI, ANI and $\mathrm{dDDH}$ values between strain $\mathrm{H} 15^{\mathrm{T}}$ and $P$. atlantica were $63.1 \%, 72.0 \%$ and $19.7 \%$, respectively. Commonly, it was suggested that AAI value of $90 \%$ and $60 \%$ were probably the threshold value for species and genus, respectively (Rodriguez-R and Konstantinidis 2014). AAI value of 63.1\% supported that strain $\mathrm{H} 15^{\mathrm{T}}$ represented a new species. Besides, the ANI and $\mathrm{dDDH}$ values of the strains were far below the recommended cut off values (95-96\% cut off for ANI and $70 \%$ for dDDH) for prokaryotic species delineation (Chun et al. 2018), and the detailed information between strain $\mathrm{H} 15^{\mathrm{T}}$ and neighbor type strains were shown in supplementary materials (Table S1).

Genome features

General features of strain $\mathrm{H} 15^{\mathrm{T}}$ genome were summarised in Table S2. The genome of strain $\mathrm{H} 15^{\mathrm{T}}$ had 4066 predicted genes of 3 rRNA operons and 40 tRNA coding with a total length of $3494520 \mathrm{bp}$. The total coverage depth was $394 \times$. The N50 and N90 value was $114996 \mathrm{bp}$ and $24994 \mathrm{bp}$, respectively.

Cluster of Orthologous Groups (COG), a protein database created and maintained by NCBI, was based on the complete genomes of bacteria, algae and eukaryotes, and the results of the COG annotation of strain $\mathrm{H} 15^{\mathrm{T}}$ were listed in Table S3. The genome contained several genes coding for amino acid transport and metabolism, translation, ribosomal structure and biogenesis, inorganic ion transport and metabolism and 
several functions unknown, which participated in several aspects of cell life activities. And the similar results were shown in the reference strain as well. Particularly, genes coding for extracellular structure, nuclear structure and cytoskeleton were not found in reference strain, which presented differences with the strain $\mathrm{H} 15^{\mathrm{T}}$. And the detailed function classification annotated by COG was shown in Fig. S2.

Specially, strain $\mathrm{H} 15^{\mathrm{T}}$ contained genes relating to the synthesis and accumulation of carotenoid pigments, which may explain why the strain $\mathrm{H} 15^{\mathrm{T}}$ was pink-pigmented. Among them, several genes such as $c r t \mathrm{I}, c r t \mathrm{~F}$ and $c r t \mathrm{~B}$ played a vital role in synthesis of lycopene, which was a red carotene and carotenoid pigment, one of the most potent antioxidants according to Narges Hedayati et al(2019). Several genes encoding enzymes involved in bioremediation were also detected in the novel strain, such as 2-halo acid dehalogenase and haloalkane dehalogenase, two key enzymes participated in chloroalkane and chloroalkene degradation, which may show activity to degrade diesel fuel.

Among Virulence Factors of Pathogenic Bacteria (VFDB) database, several genes were linked to adherence, polysaccharide capsule, pyrimidine biosynthesis, immune system evasion, flagella, protease, enzyme and others. The categories with more genes predicted were protease, such as catalase-peroxidase and urease, which was an important colonization factor, contributing to acid resistance, epithelial cell damage, chemotactic behavior and nitrogen metabolism, and also by the way of adherence associated with flagella and lipopolysaccharide (LPS) (Table S4). In addition, the secondary metabolite of strain $\mathrm{H} 15^{\mathrm{T}}$ were predicted to terpene, hserlactone, 
bacteriocin, lasso peptide and beta lactone, which were considered as important raw materials for drug synthesis.

Morphology and Phenotypic characterization

Cells were observed to be Gram-stain-negative, facultatively anaerobic, motile, gliding, lacking flagella, and rod-shaped. A pink colony with a diameter of $1.5 \mathrm{~mm}$ was obtained after incubating on MA for 3 days at $30{ }^{\circ} \mathrm{C}$ (Fig. S3). Growth was observed at $4-37{ }^{\circ} \mathrm{C}$ (optimum $33{ }^{\circ} \mathrm{C}$ ), $\mathrm{pH}$ 5.5-9.0 (optimum 7.0). The $\mathrm{NaCl}$ concentrations for growth were $0.0-7.0 \%$ (optimum 4.0\%). Strain $\mathrm{H} 15^{\mathrm{T}}$ possessed the enzymes catalase and oxidase, different from $P$. atlantica, but it was cellulase-negative and alginate-negative. Enzymatic activities determined for strain $\mathrm{H} 15^{\mathrm{T}}$ indicated positive results for alkaline phosphatase, leucine aryl amidase and acid phosphatase, with negative results for trypsin, $\alpha$-chymotrypsin, $\alpha$-galactosidase, $\beta$-glucuronidase, $N$-acetyl- $\beta$-glucosaminidase, $\alpha$-mannosidase and $\alpha$-fucosidase, and other results such as assimilation of substrates also shown highly consistency with $P$. atlantica ( $\mathrm{Li}$ et al. 2015). They all shown negative results for assimilation of phenylacetic acid, citric acid, malic acid, adipic acid, capric acid, gluconate, maltose, $\mathrm{N}$-acetyl-glucosamine, mannose, mannitol, gelatin and arabinose. Moreover, utilization of urease, esterase (C4), esterase lipase (C8), lipase (C14) and $\beta$-galactosidase were the notable characteristics to distinguish the strain $\mathrm{H} 15^{\mathrm{T}}$ from type strain of $P$. atlantica. And other phenotypic characteristics of the strain $\mathrm{H}^{1} 5^{\mathrm{T}}$ and the related strain were shown in Table 1. Furthermore, the result for negative for the 
utilization as sole carbon and energy sources a are described in Table S5. Besides, it was sensitive to penicillin, ampicillin, cephalosporin, gentamicin, erythromycin and amphenicol, resistant to amikacin.

\section{Chemotaxonomy}

The major fatty acids of strain $H 15^{\mathrm{T}}$ were identified as summed featured 8 $\left(\mathrm{C}_{18: 1} \omega 7 c / \omega 6 c, 46.1 \%\right), \mathrm{C}_{20: 1} \omega 7 c(17.6 \%)$, along with small amounts of $\mathrm{C}_{18: 0}(8.5 \%)$, $\mathrm{C}_{16: 0}(5.3 \%), \mathrm{C}_{18: 1} 2-\mathrm{OH}(5.9 \%)$ and 11-methyl 18:1 $\omega 7 c(4.9 \%)$. And the results were basically identical with the description of the reference strain ( $\mathrm{Li}$ et al. 2015). But the presence of $\mathrm{C}_{20: 1} \omega 7 c$ and $\mathrm{C}_{18: 1} 2-\mathrm{OH}$ can be used to differentiate the novel strain from the reference strain (Table 2). The polar lipids of strain $\mathrm{H} 15^{\mathrm{T}}$ were found to include phosphatidylglycerol (PG), phosphatidylethanolamine (PE), phosphatidylcholine (PC) and an unidentified lipid (L) (Fig. S4). Q10 was the predominant quinone of strain $\mathrm{H} 15^{\mathrm{T}}$.

\section{Conclusion}

Strain $\mathrm{H} 15^{\mathrm{T}}$ shared the highest similarity of $16 \mathrm{~S}$ rRNA gene sequence with $P$. atlantica $\mathrm{KCTC} 42276^{\mathrm{T}}$. The results of the phylogenetic analysis, phenotypic analysis and chemotaxonomic studies described in this study supported the view that strain $\mathrm{H} 15^{\mathrm{T}}$ should be assigned to the genus Pseudaestuariivita. However, strain $\mathrm{H} 15^{\mathrm{T}}$ could be distinguished from the reference strain by some phenotypic characteristics given in Table 1. Considering its features when compared with the most closely related specie, the strain cannot be assigned to $P$. atlantica. Therefore, strain $\mathrm{H} 15^{\mathrm{T}}$ represents a novel 

sp. nov. is proposed.

\section{Description of Pseudaestuariivita rosea sp. nov.}

Pseudaestuariivita rosea (ro'se.a. L. fem. adj. rosea referring to the color

Cells are observed to be Gram-stain-negative, facultatively anaerobic, motile, gliding, lacking flagella, and rod-shaped. The $\mathrm{pH}$ range for growth is $\mathrm{pH}$ 5.5-9.0 (optimum 7.0). Growth temperature range is between $4-37{ }^{\circ} \mathrm{C}$ with optimum growth at $33{ }^{\circ} \mathrm{C}$. The optimum concentration of $\mathrm{NaCl}$ for growth is $4.0 \%(\mathrm{w} / \mathrm{v})$. Basic enzyme content is $56.7 \%$. The Genbank accession numbers for the 16S rRNA gene sequence is MW407011 and the number for the whole genome sequence is JACNMP000000000.

\section{Acknowledgements}


We thank Prof. Aharon Oren for his valuable help with naming the species.

\section{References}

Aziz RK, Bartels D, Best AA et al. (2008) The RAST server : rapid annotations using subsystems technology. BMC Genomics:9:75. doi:10.1186/1471-2164-9-75

Blin K, Shaw S, Steinke K et al. (2019) antiSMASH 5.0: updates to the secondary metabolite genome mining pipeline. Nucleic acids research 47:W81-W87. doi:10.1093/nar/gkz310

Bowman J (2000) Description of Cellulophaga algicola sp. nov., isolated from the surfaces of Antarctic algae, and reclassification of Cytophaga uliginosa (ZoBell and Upham 1944) Reichenbach 1989 as Cellulophaga uliginosa comb. nov. International journal of systematic and evolutionary microbiology $50(\mathrm{Pt}$ 5):1861-8. doi:10.1099/00207713-50-5-1861

Chen L, Yang J, Yu J et al. (2005) VFDB: a reference database for bacterial virulence factors. Nucleic acids research 33:D325-8. doi:10.1093/nar/gki008

Chun J, Oren A, Ventosa A et al. (2018) Proposed minimal standards for the use of genome data for the taxonomy of prokaryotes. Int $\mathrm{J}$ Syst Evol Microbiol 68:461-466. doi:10.1099/ijsem.0.002516

Consortium TU (2018) UniProt: a worldwide hub of protein knowledge. Nucleic acids research 47:D506-D515. doi:10.1093/nar/gky1049

Felsenstein J (1981) Evolutionary Trees from DNA Sequences: A Maximum Likelihood Approach. J Mol Evol 17:368-376. doi:10.1007/BF01734359 
Hedayati N, Naeini MB, Nezami A et al. (2019) Protective effect of lycopene against chemical and natural toxins: A review. Biofactors 45:5-23. doi:10.1002/biof.1458

Hiraishi A, Ueda Y, Ishihara J et al. (1996) Comparative lipoquinone analysis of influent sewage and activated sludge by high-performance liquid chromatography and photodiode array detection. The Journal of General and Applied Microbiology 42:457-469. doi:10.2323/jgam.42.457

Kanehisa M, Sato Y, Kawashima M et al. (2016) KEGG as a reference resource for gene and protein annotation. Nucleic acids research 44:D457-62. doi:10.1093/nar/gkv1070

Kim M, Oh HS, Park SC et al. (2014) Towards a taxonomic coherence between average nucleotide identity and 16S rRNA gene sequence similarity for species demarcation of prokaryotes. Int J Syst Evol Microbiol 64:346-351. doi:10.1099/ijs.0.059774-0

Kimura M (1980) A simple method for estimating evolutionary rates of base substitutions through comparative studies of nucleotide sequences. Journal of Molecular Evolution 16:111-120. doi:10.1007/BF01731581

Konstantinidis KT, Tiedje JM (2005) Towards a genome-based taxonomy for prokaryotes. J Bacteriol 187:6258-64. doi:10.1128/jb.187.18.6258-6264.2005

Kumar S, Stecher G, Tamura K (2016) MEGA7: Molecular Evolutionary Genetics Analysis Version 7.0 for Bigger Datasets. Mol Biol Evol 33:1870-4. doi:10.1093/molbev/msw054 
Li GZ, Lai QL, Du YP et al. (2015) Aestuarivita atlantica sp. nov., isolated from deep-sea sediment. Int $\mathrm{J}$ Syst Evol Microbiol 65:3281-3285. doi:10.1099/ijsem.0.000406

Meier-Kolthoff JP, Auch AF, Klenk HP et al. (2013) Genome sequence-based species delimitation with confidence intervals and improved distance functions. BMC Bioinformatics 14:60. doi:10.1186/1471-2105-14-60

Minnikin DE, O'donnell AG, Goodfellow M et al. (1984) Fatty acid, polar lipid and wall amino acid composition of Gardnerella vaginalis. Arch Microbiol. 138:68-71 doi:10.1007/BF00425410

Park S, Won SM, Kim H et al. (2014) Aestuariivita boseongensis gen. nov., sp. nov., isolated from a tidal flat sediment. Int J Syst Evol Microbiol 64:2969-2974. doi:10.1099/ijs.0.062406-0

Rodriguez-R L, Konstantinidis K (2014) Bypassing cultivation to identify bacterial species: culture-independent genomic approaches identify credibly distinct clusters, avoid cultivation bias, and provide true insights into microbial species. Microbe Magazine:111-118. doi:doi:10.1128/microbe.9.111.1

Saitou N, Nei M (1987) The Neighbor-joining Method: A New Method for Reconstructing Phylogenetic Trees. Mol. Biol. Evol. 4(4):406-425. doi:10.1093/oxfordjournals.molbev.a040454

Sawant SS, Salunke BK, Kim BS (2015) A rapid, sensitive, simple plate assay for detection of microbial alginate lyase activity. Enzyme and Microbial Technology 77:8-13. doi:10.1016/j.enzmictec.2015.05.003 
Smibert RM, Krieg NR (1994) Phenotypic characterization. In: Gerhardt P, Murray RGE, Wood WA, Krieg NR (editors) Methods for General and Molecular Bacteriology. American Society for Microbiology Washington, DC. pp. 607-654.

Thompson JD, Gibson TJ, Plewniak F et al. (1997) The CLUSTAL_X windows interface: flexible strategies for multiple sequence alignment aided by quality analysis tools. Nucleic acids research 25:4876-4882. doi:10.1093/nar/25.24.4876

Tindall BJ, Sikorski J, Smibert R et al. (2007) Phenotypic charaterization and the principles of comparative systematics. In: Reddy CA, Beveridge TJ, Breznak JA, Marzluf G, Schmidt TM et al. (editors). . Methods for General and Molecular Microbiology:330-393. doi:https://doi.org/10.1128/9781555817497.ch15

Tippmann HF (2004) Analysis for free: comparing programs for sequence analysis. Brief Bioinform 5(1):82-7. doi:10.1093/bib/5.1.82

Wirth JS, Whitman WB (2018) Phylogenomic analyses of a clade within the roseobacter group suggest taxonomic reassignments of species of the genera Aestuariivita, Citreicella, Loktanella, Nautella, Pelagibaca, Ruegeria, Thalassobius, Thiobacimonas and Tropicibacter, and the proposal of six novel genera. Int J Syst Evol Microbiol 68:2393-2411. doi:10.1099/ijsem.0.002833

Yang SJ, Cho JC (2008) Gaetbulibacter marinus sp nov., isolated from coastal seawater, and emended description of the genus Gaetbulibacter. International 
journal of systematic and evolutionary microbiology 58:315-8. doi:10.1099/ijs.0.65382-0

Yin R, Yi YJ, Chen Z et al. (2021) Flavihalobacter algicola gen. nov. sp. nov., a member of the family Flavobacteriaceae with alginate-degradation activity, isolated from marine alga Saccharina japonica. Int J Syst Evol Microbiol. doi:10.1099/ijsem.0.004701

Yoon SH, Ha SM, Kwon SJ et al. (2017a) Introducing EzBioCloud: a taxonomically united database of 16S rRNA gene sequences and whole-genome assemblies. International journal of systematic and evolutionary microbiology 67:1613-1617. doi:10.1099/ijsem.0.001755

Yoon SH, Ha SM, Lim J et al. (2017b) A large-scale evaluation of algorithms to calculate average nucleotide identity. Antonie van Leeuwenhoek 110:1281-1286. doi:10.1007/s10482-017-0844-4 
Table 1. Differential characteristics of strain $\mathrm{H} 15^{\mathrm{T}}$ and other closely related member.

405 Strains: 1, H15 $;$; , Pseudaestuariivita atlantica KCTC $42276^{\mathrm{T}}$. +, Positive; -, 406 negative; w, weak.

\begin{tabular}{|c|c|c|}
\hline Characteristics & 1 & 2 \\
\hline Colony color & pink & Grey-white \\
\hline Gram-staining & - & - \\
\hline Cell size $(\mu \mathrm{m})$ & $2.5-3.0$ & $0.8-1.0 \times 1.3-1.8$ \\
\hline Gliding motility & + & - \\
\hline \multicolumn{3}{|l|}{ Growth range: } \\
\hline Temperature range (optimum, ${ }^{\circ} \mathrm{C}$ ) & $4-37 \quad(33)$ & $10-45(28)$ \\
\hline $\mathrm{NaCl}$ range for growth (optimum, w/v) & $0-7 \quad(4)$ & $1-9(3-5)$ \\
\hline $\mathrm{pH}$ range (optimum, $\%$ ) & $5.5-9.0 \quad(7.0)$ & $5-10(7-8)$ \\
\hline \multicolumn{3}{|l|}{ Enzyme activity: } \\
\hline Catalase activity & + & - \\
\hline Oxidase activity & + & - \\
\hline Esterase (C4) & $\mathrm{W}$ & - \\
\hline Lipase (C14) & - & $\mathrm{W}$ \\
\hline$\beta$-galactosidase & + & - \\
\hline Reduction of nitrate & - & - \\
\hline Ureas & + & - \\
\hline Valine arylamidase & - & $\mathrm{w}$ \\
\hline Cystine arylamidase & - & $\mathrm{w}$ \\
\hline \multicolumn{3}{|l|}{ Acids from: } \\
\hline D-mannose & + & - \\
\hline D-glucose & + & - \\
\hline D-melibiose & + & - \\
\hline \multicolumn{3}{|l|}{ Carbon source oxidation: } \\
\hline Citric acid & - & + \\
\hline
\end{tabular}


413 Table 2. Cellular fatty acid composition of strain $\mathrm{H} 15^{\mathrm{T}}$ and the closest relatives.

414 Strains: 1, H15 $;$; , Pseudaestuariivita atlantica KCTC $42276^{\mathrm{T}}$. All data were taken

415 from this study. TR, Traces $(<1.0 \%)$; -, not detected. Fatty acids amounting to $<1.0 \%$

416 of the total fatty acids in both strains are not shown.

417

\begin{tabular}{|c|c|c|}
\hline Fatty acid & 1 & 2 \\
\hline \multicolumn{3}{|l|}{ Saturated fatty acids } \\
\hline $\mathrm{C}_{9: 0}$ & TR & $\mathrm{TR}$ \\
\hline $\mathrm{C}_{10: 0}$ & TR & 1.4 \\
\hline $\mathrm{C}_{14: 0}$ & $\mathrm{TR}$ & $\mathrm{TR}$ \\
\hline $\mathrm{C}_{16: 0}$ & 5.3 & $\mathbf{1 7 . 6}$ \\
\hline $\mathrm{C}_{18: 0}$ & 8.5 & 5.1 \\
\hline $\mathrm{C}_{20: 0}$ & $\mathrm{TR}$ & TR \\
\hline \multicolumn{3}{|l|}{ Branched fatty acids } \\
\hline iso- $\mathrm{C}_{10: 0}$ & - & TR \\
\hline iso- $\mathrm{C}_{12: 0}$ & TR & - \\
\hline iso- $\mathrm{C}_{16: 1} \mathrm{H}$ & - & $\mathrm{TR}$ \\
\hline \multicolumn{3}{|l|}{ Hydroxy fatty acids } \\
\hline $\mathrm{C}_{10: 0} 3-\mathrm{OH}$ & 2.1 & TR \\
\hline $\mathrm{C}_{12: 0} 3-\mathrm{OH}$ & $\mathrm{TR}$ & $\mathrm{TR}$ \\
\hline $\mathrm{C}_{12: 1} 3-\mathrm{OH}$ & - & 6.4 \\
\hline $\mathrm{C}_{16: 0} 2-\mathrm{OH}$ & TR & TR \\
\hline $\mathrm{C}_{18: 1} 2-\mathrm{OH}$ & 5.9 & - \\
\hline $\mathrm{C}_{18: 0} 2-\mathrm{OH}$ & 3.5 & - \\
\hline \multicolumn{3}{|c|}{ Unsaturated fatty acids } \\
\hline $\mathrm{C}_{18: 1} \omega 9 c$ & $\mathrm{TR}$ & TR \\
\hline $\mathrm{C}_{20: 1} \omega 7 c$ & 17.1 & - \\
\hline iso- $\mathrm{C}_{17: 1} \omega 5 c$ & TR & $\mathrm{TR}$ \\
\hline $\mathrm{C}_{19: 0}$ cyclo $\omega 8 c$ & - & 22.3 \\
\hline Summed Feature $3^{\#}$ & $\mathrm{TR}$ & 1.1 \\
\hline Summed Feature 8* & 46.1 & 26.2 \\
\hline
\end{tabular}

$418 \quad$ \#Summed feature 3, $\mathrm{C}_{16: 1} \omega 7 c$ and/or $\mathrm{C}_{16: 1} \omega 6 c$

$419 *$ Summed feature $8, \mathrm{C}_{18: 1} \omega 7 c$ and/or $\mathrm{C}_{18: 1} \omega 6 c$ 


\section{Figures}

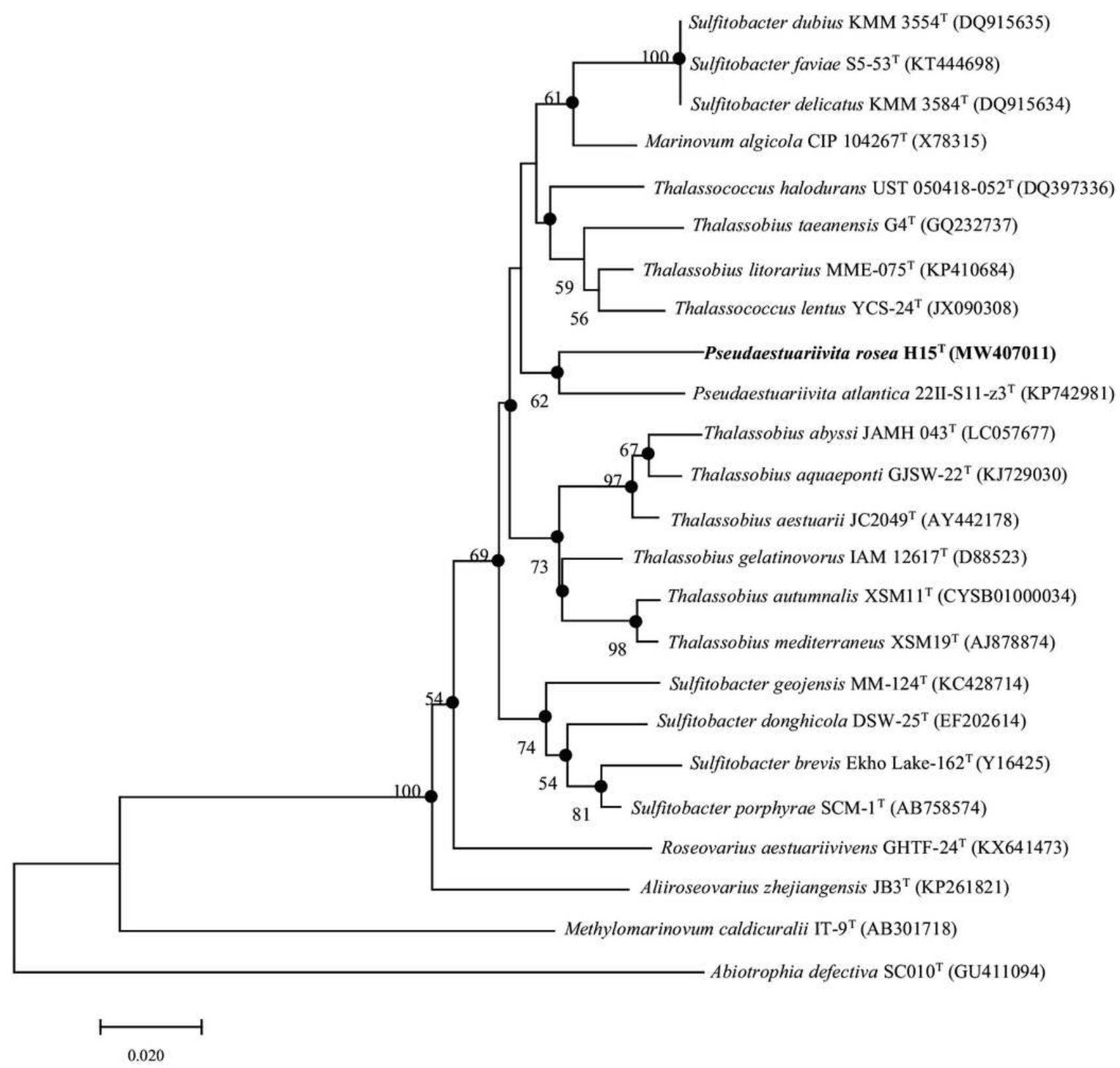

Figure 1

Neighbor-joining phylogenetic tree based on 16S rRNA gene sequences of strain MST and high similarity of genus. Bootstrap support values (1000 replications) above 50\% are shown at nodes. Abiotrophia defectiva SCO 10T was used as an outgroup. Bar, 0.02 substitutions per nucleotide position.

\section{Supplementary Files}


This is a list of supplementary files associated with this preprint. Click to download.

- Supplementarymaterials.pdf 